\title{
Transabdominal ultrasound for standardized measurement of bowel wall thickness in normal children and those with Crohn's disease
}

\author{
Liliana Chiorean ${ }^{1 *}$ Dagmar Schreiber-Dietrich $^{2 *}$, Barbara Braden ${ }^{3}, \mathrm{XinWu} \mathrm{Cui}^{2}$, \\ Christoph F. Dietrich ${ }^{2}$
}

${ }^{1}$ Department of Ultrasonography, “Octavian Fodor” Institute of Gastroenterology and Hepatology, Cluj-Napoca, Romania,
${ }^{2}$ Caritas Krankenhaus Bad Mergentheim, Bad Mergentheim, Germany, ${ }^{3}$ Translational Gastroenterology Unit, Oxford
University Hospitals, Oxford, UK

*the authors shared the first authorship

\begin{abstract}
Background: The intestinal wall can be visualized using high resolution transabdominal ultrasound (TUS). TTUS measurement of the bowel wall thickness has been described in adults but data are lacking in children. The purpose of this prospective study was to sonographically investigate bowel wall thickness in healthy children and children with Crohn's disease. Material and methods: TUS (5-15 MHz) of the intestine was performed in 58 healthy children (age range 3 to 16 years) and in 30 children with Crohn's disease (age range 8 to 17 years). The following regions were assessed and bowel wall thickness measured: terminal ileum, cecum, right flexure, and sigmoid colon. In patients with Crohn's disease, the involved region was additionally assessed regarding length of involved segment and sonographic signs of transmural inflammation and fistula. Results: TUS allowed adequate measurement of bowel wall thickness in all 58 healthy children (100\%) and in all 30 Crohn's disease patients (100\%). The bowel wall thickness significantly differed between groups. Bowel wall thickness (mean \pm SD) in all segments was less then $2 \mathrm{~mm}$ in all healthy children $(1.0 \pm 0.1 \mathrm{~mm}$ terminal ileum, $1.1 \pm 0.1 \mathrm{~mm}$ cecum, $1.1 \pm 0.1 \mathrm{~mm}$ right flexure, and $1.3 \pm 0.1 \mathrm{~mm}$ sigmoid colon). In Crohn's disease patients, bowel wall thickness was $\geq 3 \mathrm{~mm}$ in the ileocecal region and was significantly increased $(5.1 \pm 1.9 \mathrm{~mm})$ compared to the healthy children. The mean length of involved segment was $15 \pm 6.5 \mathrm{~cm}[5-30 \mathrm{~cm}]$. Additional findings in Crohn's disease patients were: transmural inflamation (3/30), interenteric fistula (3/30), gastrocolic fistula (1/30) and vesicoenteric fistula (1/30). Conclusions: Similar to adults, normal bowel wall thickness in children is always less than $2 \mathrm{~mm}$. In all patients with Crohn's disease, increased bowel wall thickness could be detected. TUS is a helpful tool in the diagnosis and assessment of activity and complications in Crohn's disease.
\end{abstract}

Keywords: Crohn's disease, bowel wall thicknes, transabdominal ultrasonography

\section{Introduction}

The intestinal wall can be visualized using high resolution transabdominal ultrasound (TUS) [1-8]. TUS measurement of bowel wall thickness (BWT) has been described in adults but data are lacking in children.

Standards for normal BWT in adults have been established by computed tomography (CT) $[9,10]$ and ul-

Received 23.07.2014 Accepted 22.09.2014

Med Ultrason

2014, Vol. 16, No 4, 319-324

Corresponding author: Prof. Dr. med. Christoph F. Dietrich Innere Medizin 2, Caritas Krankenhaus Uhlandstr. 7, D-97980 Bad Mergentheim Phone: $(+)$ 49-7931-58 2201

Fax: (+) 49-7931-58 2290

E-mail: christoph.dietrich@ckbm.de trasonography $[11,12]$. Sonographically measured mean BWT in adults ranges from 1 to $3 \mathrm{~mm}$ in the small bowel to 1 to $5 \mathrm{~mm}$ in the colon [11-13] (table I).

The aim of this prospective study was to sonographically evaluate the normal range of BWT in healthy children (HC) and to assess BWT and sonographic signs of disease activity and complications in children with established diagnosis of Crohn's disease (CD).

\section{Material and methods}

\section{Patients and controls}

In the present study, 58 HC (27 male, 31 female, mean age \pm SD $11 \pm 4$ years) and 30 patients with $C D$ and involvement of the ileocecal region with or without rectal or colonic involvement ( 9 male, 21 female, $13 \pm 2.7$ years) 
Table I. Bowel wall thickness [mm] assessed by transabdominal ultrasound at different intestinal sites in healthy adult subjects.

\begin{tabular}{ccccl}
\hline Jejunum & Ileum & Colon & $\begin{array}{c}\text { Frequency } \\
{[\mathbf{M H z}]}\end{array}$ & $\begin{array}{c}\text { Author year } \\
\text { [reference] }\end{array}$ \\
\hline$<1.1$ & $<1.4$ & $<1.8$ & 7.0 & Haber 2000 [15] \\
2.0 & 2.0 & $2.0-3.0$ & $3.5 ; 5.0$ & Worlicek 1986 [[27]] \\
$<2.0$ & $<2.0$ & $2.0-5.0$ & 5.0 & Abu-Yousef 1987 [28] \\
$<3.0$ & $<3.0$ & $<5.0$ & $3.5 ; 5.0$ & Kedar 1994 [29] \\
$<4.0$ & $<4.0$ & $<4.0$ & 5.0 & Bozkurt 1994 [30] \\
$<4.0$ & $<4.0$ & $<4.0$ & $3.5 ; 7.5$ & Maconi 1996 [31] \\
$<5.0$ & $<5.0$ & 5.0 & $2.4-5.0$ & DiCandio 1986[32] \\
$<5.0$ & $<5.0$ & $<5.0$ & na & Dubbins 1984 [33] \\
$<5.0$ & $<5.0$ & $<5.0$ & $3.5 ; 5.0$ & Sheridan 1993 [34] \\
$<3.0$ & $<3.0$ & $2.0-3.5$ & na & Odegaard 2012 [25] \\
0.9 & $1.1-1.2$ & $1.0-1.2$ & $8.0 ; 12.0$ & Nylund 2012 [26] \\
$\mathrm{Na}$ & $1.1-1.3$ & $1.1-1.3$ & 7.0 & Dialer 2003 [23] \\
\hline
\end{tabular}

Only studies using transabdominal ultrasound are included. Those trials using endoscopic ultrasound [44-48], hydrocolon ultrasound [49], in vitro measurements [50] or postmortem examination [51,52] are not included; <: indicates values below this level are considered normal; na: not available

attending our outpatient clinic were primarily enrolled during a six-month period. The diagnosis of $\mathrm{CD}$ was based on clinical, endoscopic, histological, radiological and operative findings. Patients with other than ileocecal involvement were not included. Of the 30 patients with $\mathrm{CD}, 7$ had clinically inactive disease and 23 complained about disease specific symptoms. In all patients and $\mathrm{HC}$ informed consent was obtained by parents or guardians. Institutional board approval was obtained.

\section{Ultrasound examination}

The evaluation of the bowel wall was performed by one investigator (CFD) in all patients under standardized conditions. The ultrasound method was described and validated in detail in adult patients [4]. Patients were scanned in supine position, preprandially at least 6 hours after the last meal, using 5-15 MHz curved array and linear transducers (Siemens Elegra, Erlangen, Germany. Acuson Sequoia, Siemens Erlangen, Germany). The different intestinal segments (terminal ileum, cecum, right flexure and sigmoid) could be identified in all patients. Measurement of BWT was performed ventrally in a relaxed and, therefore, not contracted bowel wall segment under mild compression. Overall thickness of the bowel wall was measured just above air from the first mucosal interface including the whole bowel wall [4]. Identifying the air might be a difference to the method used by Haber et al $[14,15]$. The layer structure was examined according to Meckler et al $[6,7]$.

In addition, in patients with $\mathrm{CD}$, the length of the involved segment (LoiS) was estimated and ultrasound signs of fistula and occurrence of free peritoneal fluid were recorded. Briefly, transmural inflammatory reaction (TMR) was recognized as transmurally extending areas with reduced echogenity and loss of normal bowel wall layer stratification, caused by cellular and edematous tissue infiltration $[4,16]$. A fistula was defined by transmurally located circumscribed bright air echoes, permeating the bowel wall within areas of inflammation [17-19].

Additionally, in all $\mathrm{HC}$ a thorough sonographic examination of the liver, gallbladder, common hepatic bile duct, pancreas, spleen, kidneys, and adrenal glands was performed in a standardized procedure $[4,20,21]$.

\section{Statistical anlysis}

Demographic, clinical and sonographic characteristics of patients were expressed as mean \pm standard deviation (SD). The minimum and maximum values of the measurements are in bracket squares. Correlations between test results and presence of disease were tested by chi-square or Fisher's exact test and $\mathrm{p}<0.05$ was considered statistically significant.

\section{Results}

All HC and CD patients even in the young ages tolerated the transabdominal ultrasound investigation of the bowel without objection. TUS allowed adeaquate measurement BWT in all $58 \mathrm{HC}(100 \%)$ and all $30 \mathrm{CD}$ $(100 \%)$.

\section{Bowel wall thickness in healthy subjects}

BWT was less then $2 \mathrm{~mm}$ in all $\mathrm{HC}$ in all bowel segments. In detail: $1.0 \pm 0.1[0.9-1.2 \mathrm{~mm}] \mathrm{mm}$ in the terminal ileum, $1.1 \pm 0.1[1.0-1.3 \mathrm{~mm}] \mathrm{mm}$ in the cecum, $1.1 \pm 0.1$ [0.9 $-1.3 \mathrm{~mm}] \mathrm{mm}$ at the right flexure, and $1.3 \pm 0.1 \mathrm{~mm}$ [1.2 -1.7 mm] in the sigmoid, respectively (table II) (fig 1).

Bowel wall thickness and additional findings in patients with Crohn's disease

In all $30 \mathrm{CD}$ patients, BWT was significantly increased as compared to $\mathrm{HC}(5.1 \pm 1.9[3.0-10] \mathrm{mm}$ versus

Table II Determination of bowel wall thickness [mm] by transabdominal ultrasound at the level of terminal ileum, ascending colon, hepatic flexure and sigmoid colon in healthy pediatric subjects $(n=58)$ and in healthy adult subjects $(n=31)$ $[1,43]$ as assessed in our unit.

\begin{tabular}{lcc}
\hline Localization & $\begin{array}{c}\text { Wall thickness } \\
(\mathbf{m m}) \text { in healthy } \\
\text { pediatric subjects }\end{array}$ & $\begin{array}{c}\text { Wall thickness } \\
\mathbf{( m m )} \text { in healthy } \\
\text { adult subjects }\end{array}$ \\
\hline Terminal ileum & $1.0 \pm 0.1[0.9-1.2]$ & $1.1+/-0.1[1.0-1.2]$ \\
Cecum & $1.1 \pm 0.1[1.0-1.3]$ & $1.1+/-0.1[0.9-1.3]$ \\
Right flexure & $1.1 \pm 0.1[0.9-1.3]$ & $1.1+/-0.1[0.9-1.3]$ \\
Sigmoid colon & $1.3 \pm 0.1[1.2-1.7]$ & $1.4+/-0.1[1.2-1.8]$ \\
\hline
\end{tabular}

The results are expressend in mean \pm standard deviation [minimum - maximum] 


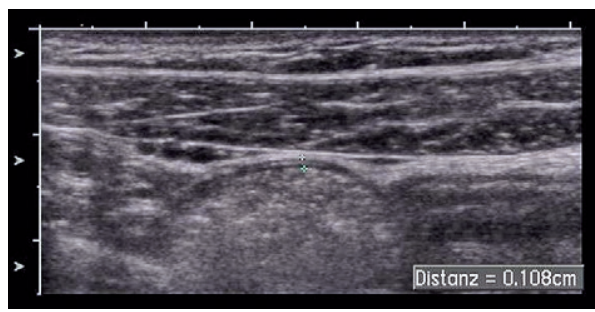

Fig 1. Normal bowel wall of the cecum in a healthy subject between markers.

$1.0 \pm 0.1[0.9-1.2 \mathrm{~mm}] \mathrm{mm}$ in the terminal ileum; $\mathrm{p}<0.001$ ) (fig 2]. Seven of the $30 \mathrm{CD}$, were clinically in remission according to a CDAI of $\leq 150$. There was a trend for higher values in patients with symptoms $(5.2 \pm 2.1 \mathrm{~mm})$ compared to patients without symptoms $(4.7 \pm 0.75 \mathrm{~mm})$ (not significant). The mean LoIS was $15 \pm 6.5 \mathrm{~cm}$ [5-30 $\mathrm{cm}]$.

The ultrasound appearance of the bowel wall layers in the ileocecal region was accentuated in 15/30 cases and lost in 6/30 patients. In 9/30 patients with BWT $<4 \mathrm{~mm}$ the bowel wall layer structure was preserved.

The presence of a TMR, representing a preliminary stage for fistula development in Crohn's disease, was detected in 3/30 CD patients (fig 3). In 5/30 CD patients fistula were detected; 3 interenteric fistula, one gastrocolic fistula, and one vesicoenteral fistula. Free fluid was found in 4/30 CD patients. TUS findings are presented in table III.

Spearman Rank correlation of bowel wall thickness and CDAI in children with Crohn's disease revealed a weak but significant association between BWT and activity index $(\mathrm{r}=0.4 ; \mathrm{p}<0.04)$ (fig 4$)$. By normal standards, the association between the two variables would be considered statistically significant.

\section{Discussions}

The intestinal wall can be visualized using high resolution TUS in healthy adults and children. The development of high resolution ultrasound transducers has facilitated the identification of the different layers of the bowel wall $[6,7,14,15]$. Linear transducers are preferable over convex probes due to the higher resolution. In some children convex probes have to be used due to anatomical reasons.

Values for TUS measured BWT are comparable for children as for adults. Differences to other published results might be explained by the method used. We require air bubbles to delineate and define the ventral luminal border of the mucosal wall layer and apply dosed compression for improved reproducibility which was not a

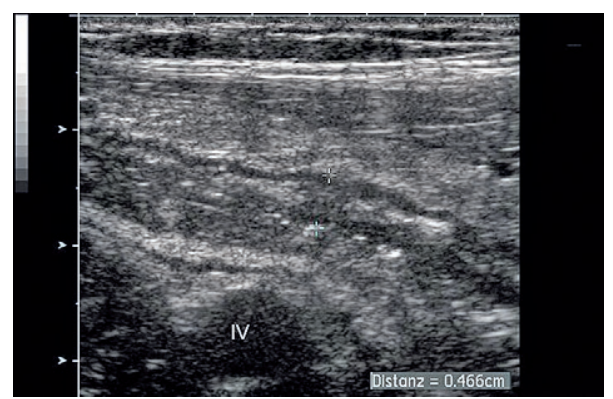

Fig 2. Slightly asymmetric bowel wall thickening (between markers, $4.7 \mathrm{~mm}$ ) in a patient with Crohn's disease. IV: iliac vessels.

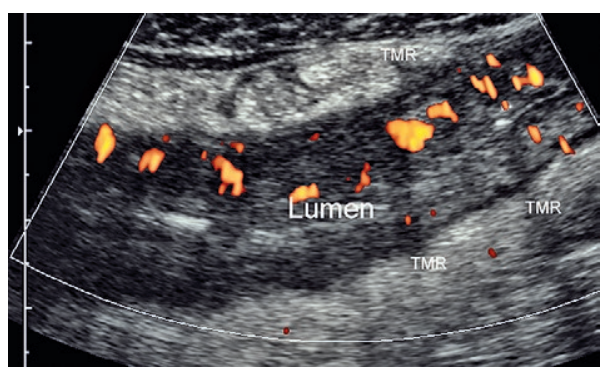

Fig 3. Transmural inflammation in a patient with Crohn's disease. The lumen is indicated as well. Power Doppler signals are seen in the submucosal layer.

Table III. Sonographically determined intestinal manifestation in children with Crohn's disease.

\begin{tabular}{ll}
\hline Sonographic findings & \\
\hline Bowel wall thickening [mm] & $5.1 \pm 1.9[3.0-10]$ \\
Transmural inflammatory reaction (TMR) & $3 / 30(10 \%)$ \\
Interenteric fistula & $3 / 30(10 \%)$ \\
Gastrocolic fistula & $1 / 30(3.33 \%)$ \\
Vesicoenteric fistula & $1 / 30(3.33 \%)$ \\
Ascites & $4 / 30(13.33 \%)$ \\
\hline
\end{tabular}

The results are expressend in mean \pm standard deviation [minimum - maximum] or percent.

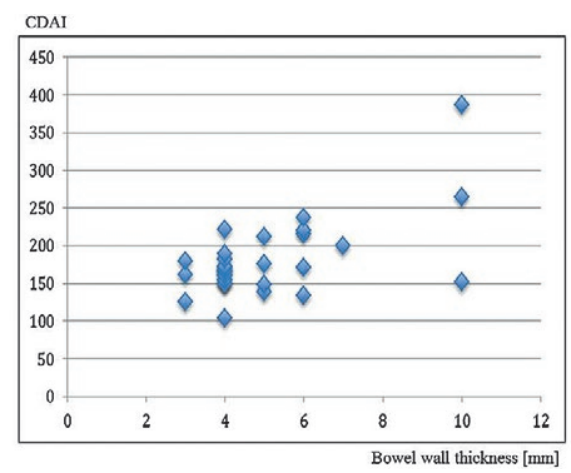

Fig 4. Spearman Rank correlation of bowel wall thickness and CDAI in 30 children with Crohn's disease $(r=0.4 ; \mathrm{p}<0.04)$. 
described criterion in other studies [14,15]. Comparing our data in children to those in adults from our previous studies (table II), age dependent differences in BWT were not obvious, but a trend was reported by Haber et al [15].

MacSweeney et al [22] examined 38 healthy subjects (age range, 1 month to 39 years) and found that the maximum colon wall thickness was $0.8 \mathrm{~mm}$. Haber et al [15] performed TUS of the small bowel and the colon in 128 subjects (age range, 3 days to 40 years). They found that BWT increased significantly $(\mathrm{p}<0.0001)$ with age, reaching a maximum colon wall thickness of $2.0 \mathrm{~mm}$ at the age of 20 to 29 years. In the ileum, maximum bowel wall thickness reached $1.5 \mathrm{~mm}$ at the age range of 10 to 14 years. Haber et al [14] also sonographically evaluated 46 healthy patients ( 22 females) with a mean age of 17 (SD 11.3) (median 13; range 0.4-40) years. Maximum thickness of the wall of the small intestine was $1.5 \mathrm{~mm}$ and maximum thickness of the colon wall was $1.9 \mathrm{~mm}$. There was a slight, but significant $(r=-0594 ; p<0.001)$ increase with age. Dialer et al [23] sonographically evaluated bowel wall thickness at the level of terminal ileum, cecum, ascending and descending colon in 31 healthy probands (mean 13.3 years, range 0.7-32), representing a control group for their study evaluating bowel wall thickness in patients with cystic fibrosis. Mean wall thickness depending on the intestinal segment was 1.1 to $1.3 \mathrm{~mm}$ (SD $0.19-0.23$ ). Robinson et al [24] performed ultrasound measurements in 13 healthy infants with an average age of 7.3 months, and found a mean distal ileum wall thickness of $2.0 \mathrm{~mm}$.

Summarising published data normal values of BWT differ between methods of measurements with a wide range, from 1 up to $5 \mathrm{~mm}$ [23,25-34]. Using ultrasound, values ranging from $1.5 \mathrm{~mm}$ to $3 \mathrm{~mm}$ for the terminal ileum and $<2 \mathrm{~mm}$ for the colon have been suggested as normal in various reports [35]. In our experience, values for normal intestinal thickness measured by TUS are even lower, being less than $2 \mathrm{~mm}$ in all small and large bowel segments when examined with mild compression. These results have been confirmed in the literature [25], and may be due to the examination technique (especially mild externally exerted compression), equipment and frequencies used [1].

Measurements by CT in adult controls show values for normal BWT of 1-2 $\mathrm{mm}$ when the lumen is well distended [36-38]. Data on normal BWT measured by CT in children are lacking. On MRI, BWT of more than $3 \mathrm{~mm}$ is considered pathologic in the pediatric population [39].

When assessing BWT using ultrasound, values can be lower than by using other imaging techniques due to the measurements under mild compression [1]. Bowel wall thickening is not a pathognomonic finding in inflamma- tory bowel disease. A large spectrum of other intestinal diseases can also lead to thickening of the bowel wall, infectious, vascular, or neoplastic conditions should also be considered [11,14,40,41].

TUS is a useful examination technique to determine morphological alterations of the bowel wall associated with active CD compared to $\mathrm{HC}[12,42]$. In contrast to endoscopic procedures, which are generally restricted to the evaluation of the mucosal surface, ultrasonography is able to confirm transmural inflammatory activity [4]. In addition, it could be shown that routinely performed ultrasonography of the abdomen reveals pathological findings with therapeutic implications not only in symptomatic but also in asymptomatic patients with Crohn's disease [4]. As endoscopic techniques in children usually require deep sedation, the non-invasiveness of the TUS not even requiring bowel preparation is intriguing.

In adults, attempts have been made to correlate wall thickness with disease activity particularly Crohn's disease activity index (CDAI); the results have been summarized [43]. In a large series of 255 patients, it was evidenced that wall thickness is significantly higher in $\mathrm{CD}$ compared to normal $(4.9+/-2.7 \mathrm{~mm}$ versus $<2.0$ $\mathrm{mm})$ and greater in active (CDAI $>150)$ than in inactive disease (CDAI <150): $5.8+/-2.9 \mathrm{~mm}$ versus $4.3+/-2.2$ $(\mathrm{p}<0.0001))$ [4]. In a smaller unpublished trial including 92 consecutive adult patients a weak but significant association (correlation) of BWT with the CDAI was found $\left(\mathrm{R}_{\mathrm{s}}: 0.44, \mathrm{p}<0.00001\right)$ [43]. In our study, a weak but significant association between BWT and activity index could also be seen in children.

Ultrasound has been used as screening procedure in adults to evaluate the bowel wall and extraintestinal manifestations in inflammatory bowel diseases [20] but data are still lacking in children. Ultrasound has also proven to be of value in similar diseases compared to inflammatory bowel diseases $[1,2,21,43]$.

In conclusion, ultrasound is a valuable tool for the quantitative assessment of normal and pathological BWT in children. In HC, the normal bowel wall is less than 2 $\mathrm{mm}$ in the terminal ileum and throughout the colon. In children with $\mathrm{CD}$, the BWT is increased, often even in quiescent disease.

Conflict of interest: none

\section{References}

1. Dietrich CF, Brunner V, Lembcke B. [Intestinal ultrasound in rare small and large intestinal diseases]. Z Gastroenterol 1998; 36: 955-970. 
2. Dietrich CF, Brunner V, Seifert H, Schreiber-Dietrich D, Caspary WF, Lembcke B. [Intestinal B-mode sonography in patients with endemic sprue. Intestinal sonography in endemic sprue]. Ultraschall Med 1999; 20: 242-247.

3. Gritzmann N, Hollerweger A, Macheiner P, Rettenbacher T. Transabdominal sonography of the gastrointestinal tract. Eur Radiol 2002; 12: 1748-1761.

4. Hirche TO, Russler J, Schroder O et al. The value of routinely performed ultrasonography in patients with Crohn disease. Scand J Gastroenterol 2002; 37: 1178-1183.

5. Hollerweger A, Rettenbacher T, Macheiner P, Brunner W, Gritzmann N. Sigmoid diverticulitis: value of transrectal sonography in addition to transabdominal sonography. AJR Am J Roentgenol 2000; 175: 1155-1160.

6. Meckler U, Herzog P. [Sonographic structure of the intestinal wall--significance for the diagnosis of inflammatory intestinal diseases]. Ultraschall Med 1989; 10: 152-157.

7. Meckler U, Caspary WF, Clement T et al. [Sonography in Crohn disease--the conclusions of an experts' group]. Z Gastroenterol 1991; 29: 355-359.

8. Rettenbacher T, Hollerweger A, Macheiner P et al. Outer diameter of the vermiform appendix as a sign of acute appendicitis: evaluation at US. Radiology 2001; 218: 757 762.

9. Fisher JK. Normal colon wall thickness on CT. Radiology 1982; 145: 415-418.

10. Desai RK, Tagliabue JR, Wegryn SA, Einstein DM. CT evaluation of wall thickening in the alimentary tract. Radiographics 1991; 11: 771-783.

11. Hata J, Haruma K, Suenaga K et al. Ultrasonographic assessment of inflammatory bowel disease. Am J Gastroenterol 1992; 87: 443-447.

12. Worlicek H, Lutz H, Heyder N, Matek W. Ultrasound findings in Crohn's disease and ulcerative colitis: a prospective study. J Clin Ultrasound 1987; 15: 153-163.

13. Fleischer AC, Muhletaler CA, James AE, Jr. Sonographic assessment of the bowel wall. AJR Am J Roentgenol 1981; 136: 887-891.

14. Haber HP, Benda N, Fitzke G et al. Colonic wall thickness measured by ultrasound: striking differences in patients with cystic fibrosis versus healthy controls. Gut 1997; 40: 406-411.

15. Haber HP, Stern M. Intestinal ultrasonography in children and young adults: bowel wall thickness is age dependent. J Ultrasound Med 2000; 19: 315-321.

16. Alison M, Kheniche A, Azoulay R, Roche S, Sebag G, Belarbi N. Ultrasonography of Crohn disease in children. Pediatr Radiol 2007; 37: 1071-1082.

17. Orsoni P, Barthet M, Portier F, Panuel M, Desjeux A, Grimaud JC. Prospective comparison of endosonography, magnetic resonance imaging and surgical findings in anorectal fistula and abscess complicating Crohn's disease. $\mathrm{Br}$ J Surg 1999; 86: 360-364.

18. Maconi G, Sampietro GM, Parente F et al. Contrast radiology, computed tomography and ultrasonography in detecting internal fistulas and intra-abdominal abscesses in Crohn's disease: a prospective comparative study. Am J Gastroenterol 2003; 98: 1545-1555.
19. Gasche C, Moser G, Turetschek K, Schober E, Moeschl P, Oberhuber G. Transabdominal bowel sonography for the detection of intestinal complications in Crohn's disease. Gut 1999; 44: 112-117.

20. Hirche TO, Russler J, Braden B et al. Sonographic detection of perihepatic lymphadenopathy is an indicator for primary sclerosing cholangitis in patients with inflammatory bowel disease. Int J Colorectal Dis 2004; 19: 586-594.

21. Dietrich CF, Chichakli M, Hirche TO et al. Sonographic findings of the hepatobiliary-pancreatic system in adult patients with cystic fibrosis. J Ultrasound Med 2002; 21: 409416.

22. Mac Sweeney EJ, Oades PJ, Buchdahl R, Rosenthal M, Bush A. Relation of thickening of colon wall to pancreatic-enzyme treatment in cystic fibrosis. Lancet 1995; 345: 752-756.

23. Dialer I, Hundt C, Bertele-Harms RM, Harms HK. Sonographic evaluation of bowel wall thickness in patients with cystic fibrosis. J Clin Gastroenterol 2003; 37: 55-60.

24. Robinson CG, Hernanz-Schulman M, Zhu Y, Griffin MR, Gruber W, Edwards KM. Evaluation of anatomic changes in young children with natural rotavirus infection: is intussusception biologically plausible? J Infect Dis 2004; 189: 1382-1387.

25. Odegaard S, Nesje LB, Laerum OD, Kimmey MB. Highfrequency ultrasonographic imaging of the gastrointestinal wall. Expert Rev Med Devices 2012; 9: 263-273.

26. Nylund K, Hausken T, Odegaard S, Eide GE, Gilja OH. Gastrointestinal wall thickness measured with transabdominal ultrasonography and its relationship to demographic factors in healthy subjects. Ultraschall Med 2012; 33: E225-E232.

27. Worlicek H, Lutz H, Thoma B. [Sonography of chronic inflammatory bowel diseases--a prospective study]. Ultraschall Med 1986; 7: 275-280.

28. Abu-Yousef MM, Bleicher JJ, Maher JW, Urdaneta LF, Franken EA, Jr., Metcalf AM. High-resolution sonography of acute appendicitis. AJR Am J Roentgenol 1987; 149: 5358.

29. Kedar RP, Shah PP, Shivde RS, Malde HM. Sonographic findings in gastrointestinal and peritoneal tuberculosis. Clin Radiol 1994; 49: 24-29.

30. Bozkurt T, Richter F, Lux G. Ultrasonography as a primary diagnostic tool in patients with inflammatory disease and tumors of the small intestine and large bowel. J Clin Ultrasound 1994; 22: 85-91.

31. Maconi G, Parente F, Bollani S, Cesana B, Bianchi PG. Abdominal ultrasound in the assessment of extent and activity of Crohn's disease: clinical significance and implication of bowel wall thickening. Am J Gastroenterol 1996; 91: 16041609.

32. DiCandio G, Mosca F, Campatelli A, Bianchini M, D'Elia F, Dellagiovampaola C. Sonographic detection of postsurgical recurrence of Crohn disease. AJR Am J Roentgenol 1986; 146: 523-526.

33. Dubbins PA. Ultrasound demonstration of bowel wall thickness in inflammatory bowel disease. Clin Radiol 1984; 35: $227-231$. 
34. Sheridan MB, Nicholson DA, Martin DF. Transabdominal ultrasonography as the primary investigation in patients with suspected Crohn's disease or recurrence: a prospective study. Clin Radiol 1993; 48: 402-404.

35. Haber HP, Busch A, Ziebach R, Stern M. Bowel wall thickness measured by ultrasound as a marker of Crohn's disease activity in children. Lancet 2000; 355: 1239-1240.

36. Macari M, Balthazar EJ. CT of bowel wall thickening: significance and pitfalls of interpretation. AJR Am J Roentgenol 2001; 176: 1105-1116

37. Macari M, Megibow AJ, Balthazar EJ. A pattern approach to the abnormal small bowel: observations at MDCT and CT enterography. AJR Am J Roentgenol 2007; 188: 1344-1355.

38. Wittenberg J, Harisinghani MG, Jhaveri K, Varghese J, Mueller PR. Algorithmic approach to CT diagnosis of the abnormal bowel wall. Radiographics 2002; 22: 1093-1107.

39. Mentzel HJ, Reinsch S, Kurzai M, Stenzel M. Magnetic resonance imaging in children and adolescents with chronic inflammatory bowel disease. World J Gastroenterol 2014; 20: 1180-1191.

40. Siegel MJ, Friedland JA, Hildebolt CF. Bowel wall thickening in children: differentiation with US. Radiology 1997; 203: 631-635.

41. Akcalar S, Turkbey B, Karcaaltincaba M, Akpinar E, Akhan O. Small bowel wall thickening: MDCT evaluation in the emergency room. Emerg Radiol 2011; 18: 409-415.

42. Sandhu BK, Fell JM, Beattie RM, Mitton SG, Wilson DC, Jenkins $\mathrm{H}$. Guidelines for the management of inflammatory bowel disease in children in the United Kingdom. J Pediatr Gastroenterol Nutr 2010; 50 Suppl 1: S1-13.

43. Allgayer H, Braden B, Dietrich CF. Transabdominal ultrasound in inflammatory bowel disease. Conventional and recently developed techniques-update. Med Ultrason 2011; 13: 302-313

44. Wijers OB, Tio TL, Tytgat GN. Ultrasonography and endosonography in the diagnosis and management of inflammatory bowel disease. Endoscopy 1992; 24: 559-564.

45. Faure C, Belarbi N, Mougenot JF et al. Ultrasonographic assessment of inflammatory bowel disease in children: comparison with ileocolonoscopy. J Pediatr 1997; 130: 147-151.

46. Dagli U, Over H, Tezel A, Ulker A, Temucin G. Transrectal ultrasound in the diagnosis and management of inflammatory bowel disease. Endoscopy 1999; 31: 152-157.

47. Gast P. Endorectal ultrasound in infectious colitis may predict development of chronic colitis. Endoscopy 1999; 31: 265-268.

48. Soweid AM, Chak A, Katz JA, Sivak MV, Jr. Catheter probe assisted endoluminal US in inflammatory bowel disease. Gastrointest Endosc 1999; 50: 41-46.

49. Limberg B. Diagnosis and staging of colonic tumors by conventional abdominal sonography as compared with hydrocolonic sonography. N Engl J Med 1992; 327: 65-69.

50. Limberg B. Sonographic features of colonic Crohn's disease: comparison of in vivo and in vitro studies. J Clin Ultrasound 1990; 18: 161-166.

51. Kimmey MB, Wang KY, Haggitt RC, Mack LA, Silverstein FE. Diagnosis of inflammatory bowel disease with ultrasound. An in vitro study. Invest Radiol 1990; 25: 10851090.

52. Kimmey MB, Martin RW, Haggitt RC, Wang KY, Franklin DW, Silverstein FE. Histologic correlates of gastrointestinal ultrasound images. Gastroenterology 1989; 96: 433441 . 